\title{
Systematic review of pleural-amniotic shunt insertion vs. conservative management in isolated bilateral fetal hydrothorax without hydrops
}

\author{
Elaine Carson ${ }^{1}$ (D) Priscilla Devaseelan ${ }^{1} \cdot$ Stephen Ong ${ }^{1}$ \\ Received: 12 March 2019 / Accepted: 4 September 2019 / Published online: 19 November 2019 \\ (C) The Author(s) 2019
}

\begin{abstract}
Objective In the management of bilateral fetal hydrothorax where the fetus is non-hydropic and apparently otherwise normal, we wished to determine if pleural-amniotic shunt insertion was better than conservative management in terms of mortality.

Methods A systematic review was conducted between 1992 and 2017. Data extracted was inspected for heterogeneity. Where there was comparative data available, the odds ratio (OR) and confidence interval (CI) were calculated.

Results Seven studies were included in this systematic review. There was a paucity of comparative data where only 2 studies ( 28 cases) allowed for direct comparison. Within the limitations of the study, there was no difference between shunt insertion vs. conservative management in terms of stillbirth or miscarriage ( $\mathrm{OR}=1.00,95 \% \mathrm{CI} 0.12-8.34$, heterogeneity $I^{2}=0 \%, p=1.00$ ). Conclusion There is insufficient data available to determine whether the outcome is improved by pleural-amniotic shunt insertion compared with conservative management in cases of bilateral fetal hydrothorax where the fetus is non-hydropic and otherwise normal.
\end{abstract}

Keywords Fetal therapy $\cdot$ Hydrothorax $\cdot$ Pleural effusion $\cdot$ Shunt $\cdot$ Thoracoamniotic shunting

\section{Introduction}

In a pregnancy complicated by a fetus with primary bilateral hydrothorax with no other identifiable anomaly, the decision for pleural-amniotic shunt insertion or conservative management can be a therapeutic dilemma. Most clinicians faced with this clinical situation would consider shunt insertion in the presence of hydrops on the grounds that conservative management would likely result in fetal demise. If, however, the fetus was not hydropic, many clinicians would adopt a conservative approach while others would offer shunt insertion.

Given that pleural-amniotic shunt insertion is not without risk, with a procedure-related loss rate of about $1 \%$, this question merits investigation. In this paper, we propose to study pregnancy where the fetus has primary bilateral hydrothorax with no other anomaly and is not hydropic. We wished to

Elaine Carson

ecarson05@qub.ac.uk

1 Fetal Medicine department, Royal Jubilee Maternity Hospital, Grosvenor Road Belfast BT12 6BB UK perform a systematic review of shunt insertion vs. conservative management in these cases.

\section{Materials and methods}

This systematic review was based on a protocol developed using widely recommended methods for the systematic review of observational studies [10, 12, 21, 23; Henderson et al. 2009]. The study was registered with the PROSPERO database (registration number CRD42017060485; www.crd. york.ac.uk/PROSPERO).

\section{Search strategy}

The search strategy involved searching the bibliographic databases MEDLINE and EMBASE, the Cochrane library and Web of Science between March 1992 and March 2017 inclusive, and followed the PRISMA guidelines [14]. The search terms used were "fetus, fetal, foetus, and foetal in combination with hydrothorax, chylothorax, pleural effusion, thoracoamniotic shunt, and shunting. A combination of $\mathrm{MeSH}$ and text words was used. All relevant abstracts were 
reviewed and where the abstract met the pre-defined selection criteria, the full article was retrieved and reviewed. No language restriction was applied. Experts in the area were consulted to ensure the review encompassed all relevant papers.

\section{Study selection}

Selection criteria were the following:

- Population-Pregnancies with non-hydropic fetuses with primary bilateral fetal hydrothorax managed with thoracoamniotic shunting or conservative management.

- Outcome - intrauterine demise (stillbirth or miscarriage), neonatal death.

- Study design-Prospective and retrospective studies including case series involving more than 5 cases.

\section{Quality assessment and data extraction}

One reviewer (EC) extracted the data from all the papers meeting the selection criteria. This was checked by another reviewer (SO). The studies were assessed for quality using the Strengthening the Reporting of Observational Studies in Epidemiology (STROBE) statement criteria [23] and the following criteria were derived from the checklist [18]:
- Data collection-Prospective data was considered ideal; retrospective collection was considered second best.

- Description of population-A well-defined sample at a uniform early stage with clear documentation of gestation at diagnosis, gestation at intervention, and delivery was considered ideal.

- Prognostic factors considered: Clear documentation of other anomalies was considered ideal.

- Objective outcome - Clear documentation of intrauterine demise or neonatal death was considered ideal.

- Outcome ascertainment-Greater than $90 \%$ follow-up of the original study population was considered ideal, less than $90 \%$ was considered second best.

\section{Data synthesis}

The extracted data were tabulated to allow qualitative inspection for clinical and methodological heterogeneity. The data were not weighted according to the quality of the paper. For comparison of dichotomous outcomes between groups, the odds ratio (OR) and standard errors were calculated for the association in each study. The heterogeneity of estimates was explored graphically using forest plots and formally tested using $\chi^{2}$ tests. A combined proportion was calculated using the random effects models on the log odds scale. Data from individual studies were pooled [6]. The analysis of odds ratios was conducted using Review Manger 5 [1].
Fig. 1 Prisma flow diagram demonstrating study selection

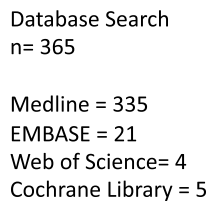

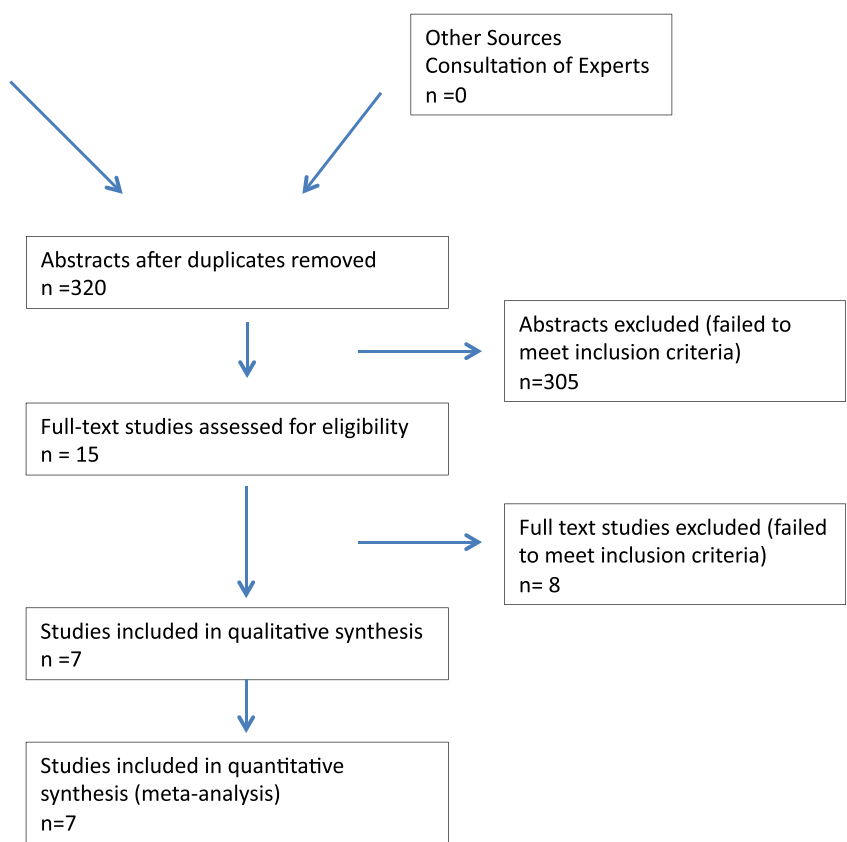




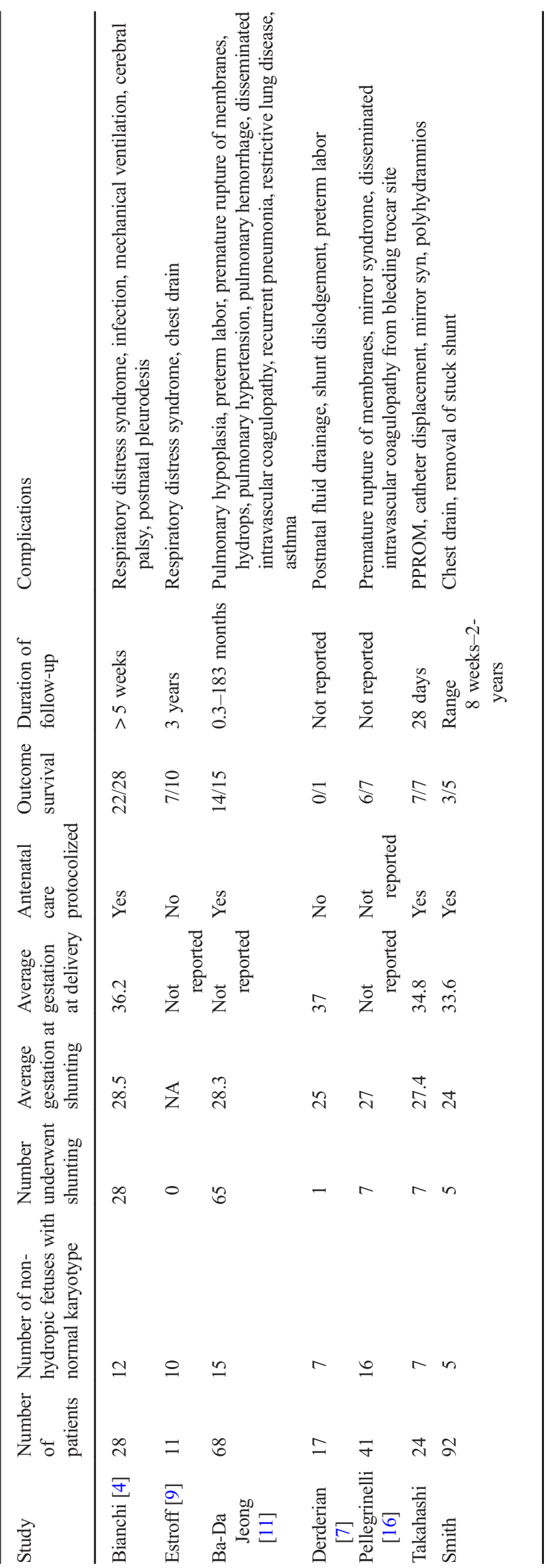


Fig. 2 Quality assessment of studies in the systematic review using clinically important criteria

Total Number of patients recruited

$$
\begin{array}{r}
\text { Data collection } \\
\text { Patient Enrolment } \\
\text { Gestational age at presentation }
\end{array}
$$

Number underwent shunting

Gestational age at shunting

$$
\text { Percentage follow up }
$$

Antenatal care protocolised

Gestational Age at Diagnosis

Other Anomalies

Karyotype

\section{Results}

\section{Identification of the literature}

The electronic search of bibliographical databases yielded 335 citations, of which 15 were considered potentially relevant [3-5, 7-9, 11, 13, 15-17, 19, 20, 22, 24]. Examination of the full manuscripts revealed that 8 did not meet the selection criteria. Thus, a total of 7 primary studies $[4,7,9,11,16,20$, 22] were selected for review (Fig. 1; Table 1). All studies were retrospective observational studies.

\section{Study characteristics and quality}

The quality assessment of included studies is demonstrated in

Figs. 2 and 3. The gestational age at diagnosis was reported in

\section{Quality Assessment}

ares - No/ Unclear
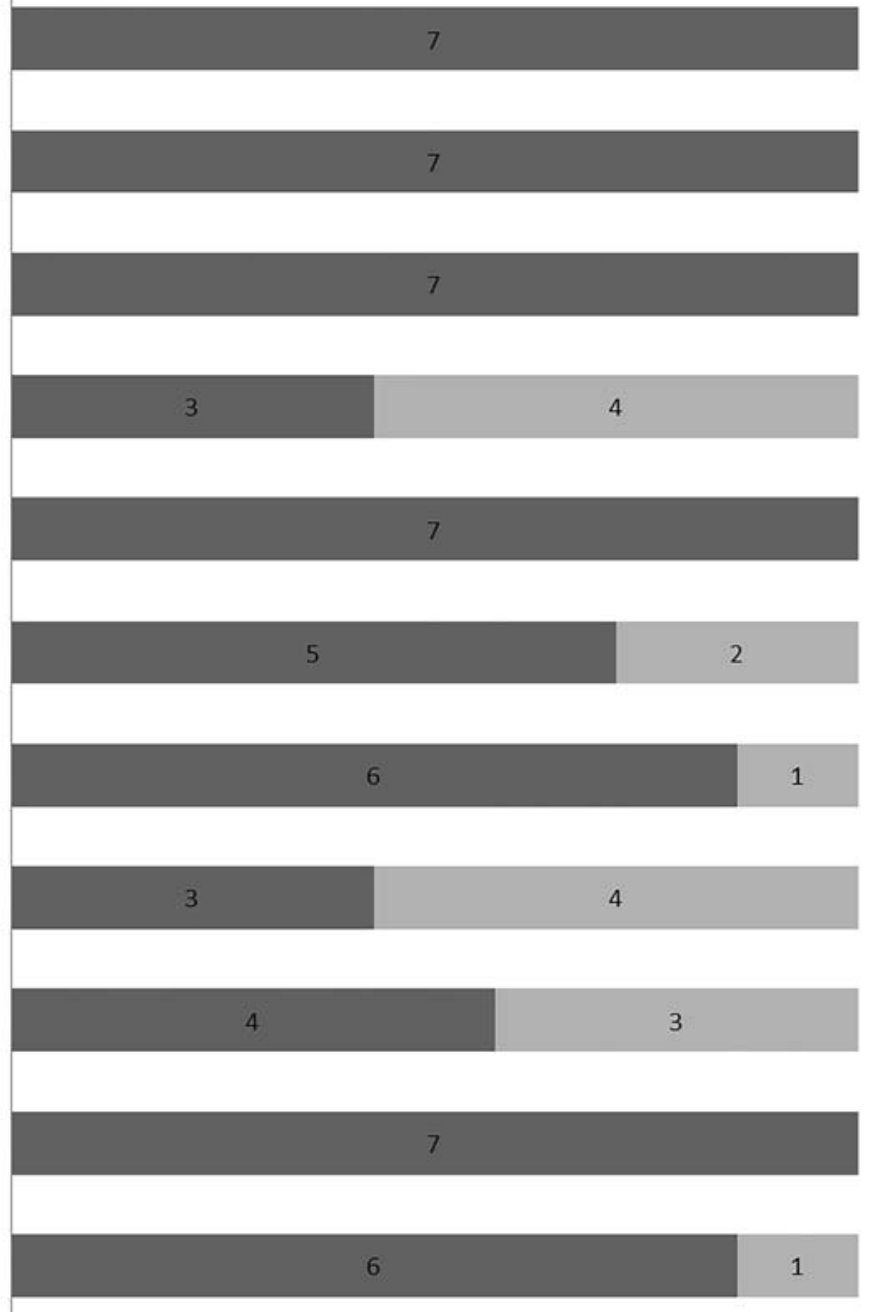

$43 \%$ of studies. Gestation at shunt insertion was reported in $72 \%$ of studies.

\section{Survival rates following shunt insertion vs. conservative management}

Only 2 of the 7 selected studies had direct comparative data of conservative management vs. pleural-amniotic shunting (Fig. 4).

There was a paucity of comparative data where only 2 studies (28 cases) allowed for direct comparison. Within the limitations of the study, there was no difference between shunt insertion vs. conservative management in terms of stillbirth or miscarriage $(\mathrm{OR}=1.00,95 \%$ CI $0.12-8.34$, heterogeneity $\left.I^{2}=0 \%, p=1.00\right)$. 
Fig. 3 Quality assessment of studies in the systematic review (STROBE criteria)

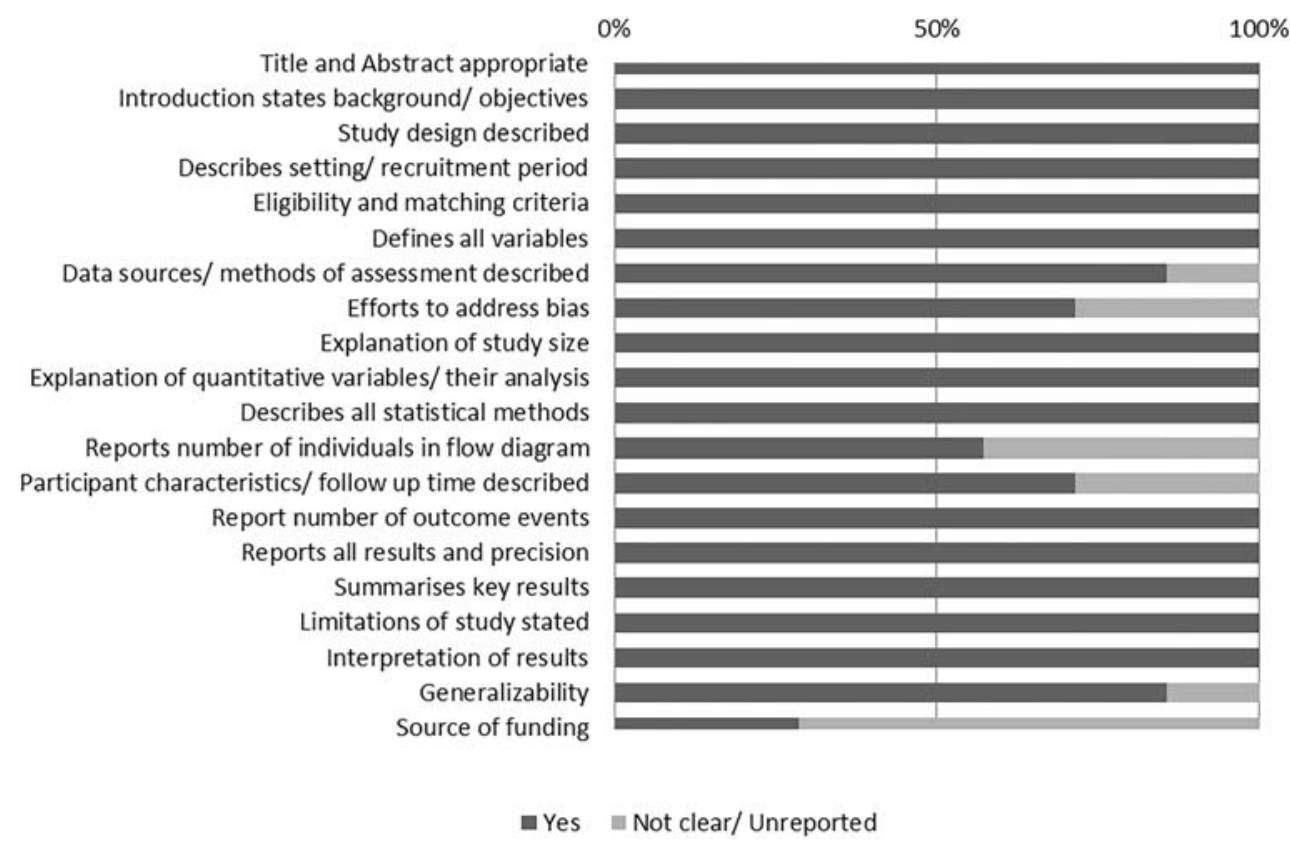

Title and Abstract appropriate Study design described 要 要

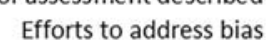
Explanation of study size titative variables/ their analysis teristics/ follow up time described eport number of outcome events all results and precision Summarises key results
Limitations of study stated
Interpretation of results Generalizability Source of funding

Yes Not clear/ Unreported

\section{Discussion}

This systematic review did not provide sufficient evidence for or against pleural-amniotic shunting in cases of bilateral hydrothorax where the fetus is non-hydropic and apparently otherwise normal. The number of cases was too small to reach a meaningful conclusion.

The strength of this review is that it employed an exhaustive research strategy. This way, we were able to collate evidence for a condition that is imprecisely assessed in individual studies. In addition, the quality of these studies was assessed.

A major weakness of this systematic review is that all the papers evaluated were retrospective in nature and the overall number of cases was very small.

A further weakness of this review is that subtle reasons whereby decision-making may change are not accounted for. For example, a clinician may see a woman with a nonhydropic fetus with bilateral hydrothorax at 20 weeks. He may decide to adopt a conservative approach as the fetus is in a difficult position for shunt insertion. By 24 weeks, the clinical picture may be the same but the fetus could be in a better position for shunt insertion. The clinician may well decide to opt for shunt insertion. Our systematic review would have classified such a case as an intervention. In reality, a period of conservative management followed by shunt insertion took place.

In the original conception of this systematic review, we hoped to study outcome at different gestations, i.e., 20 to 24 weeks, 24 to 28 weeks, 28 to 32 weeks, and 32 to 34 weeks. We were particularly keen to study the outcome at the later gestations, where iatrogenic premature delivery (with its attendant risk of morbidity and mortality) is a possibility. Due to the paucity of our data, we were not able to provide useful information at different gestations.

\section{Conclusion}

In cases of bilateral fetal hydrothorax, where the fetus is nonhydropic and otherwise structurally normal, the correct management strategy in terms of pleural-amniotic shunting or conservative management remains unknown.
Fig. 4 Comparison of shunt insertion versus conservative management. Meta-analysis of the outcomes of stillbirth or miscarriage

\begin{tabular}{|c|c|c|c|c|c|c|c|c|c|}
\hline Study or Subgroup & Shunt & Total & \multicolumn{2}{|c|}{ Conservative } & Weight & $\begin{array}{c}\text { Odds Ratio } \\
\text { M-H, Fixed, } 95 \% \mathrm{Cl}\end{array}$ & \multicolumn{3}{|c|}{$\begin{array}{c}\text { Odds Ratio } \\
\text { M-H, Fixed, } 95 \% \mathrm{Cl}\end{array}$} \\
\hline Ba-Da Jeong 2015 & 14 & 65 & 0 & 0 & & Not estimable & & & \\
\hline Bianchi 2010 & 6 & 28 & 0 & 0 & & Not estimable & & & \\
\hline Derderian 2014 & 1 & 2 & 5 & 10 & $48.8 \%$ & $1.00[0.05,20.83]$ & & & \\
\hline Estroff 1992 & 0 & 0 & 4 & 11 & & Not estimable & & & \\
\hline Pellegrinelli 2012 & 7 & 14 & 1 & 2 & $51.2 \%$ & $1.00[0.05,19.36]$ & & & \\
\hline Smith 2005 & 2 & 5 & 0 & 0 & & Not estimable & & & \\
\hline Takahashi 2012 & 7 & 14 & 0 & 0 & & Not estimable & & & \\
\hline Total $(95 \% \mathrm{Cl})$ & & 128 & & 23 & $100.0 \%$ & $1.00[0.12,8.34]$ & & & \\
\hline Total events & 37 & & 10 & & & & & & \\
\hline \multicolumn{5}{|c|}{$\begin{array}{l}\text { Heterogeneity: } \mathrm{Chi}^{2}=0.00, \mathrm{df}=1(\mathrm{P}=1.00) ; \mathrm{I}^{2}=0 \% \\
\text { Test for overall effect: } Z=0.00(P=1.00)\end{array}$} & & & 0.01 & $\begin{array}{l}0.1 \\
\text { Favours shunt }\end{array}$ & $\left.\right|_{\text {Favours conservative }} ^{10} 100$ \\
\hline
\end{tabular}


A multicenter randomized controlled trial is the best way to answer this question but may prove to be an impossible undertaking. Another solution would be for several large units to standardize reporting at the outset and pool their respective results in a large observational study.

\section{Summary}

In a pregnancy complicated by a fetus with primary hydrothorax and no other identifiable anomaly, we wished to determine whether pleural-amniotic shunt insertion was better than conservative management in terms of mortality. To do this, we conducted a systematic review between 1992 and 2017 and identified seven studies from which we could extract data. There was a paucity of comparative data with only two studies allowing for direct comparison. Within the limitations of the review, there was no difference between shunt insertion vs. conservative management.

\section{Compliance with ethical standards}

Conflict of interest The authors declare that they have no conflict of interest.

Open Access This article is distributed under the terms of the Creative Commons Attribution 4.0 International License (http:// creativecommons.org/licenses/by/4.0/), which permits unrestricted use, distribution, and reproduction in any medium, provided you give appropriate credit to the original author(s) and the source, provide a link to the Creative Commons license, and indicate if changes were made.

\section{References}

1. (2008) Review Manager (RevMan) 5th edn. The Nordic Cochrane Centre, The Cochrane Collaboration, Copenhagen

2. (2009) NHS Centre for Reviews and Dissemination CRD's guidance for undertaking reviews in health care. In: York UO (ed). York

3. Bernaschek G, Deutinger J, Hansmann M, Bald R, Holzgreve W, Bollmann R (1994) Feto-amniotic shunting-report of the experience of four European centres. Prenat Diagn 14:821-833

4. Bianchi S, Lista G, Castoldi F, Rustico M (2010) Congenital primary hydrothorax: effect of thoracoamniotic shunting on neonatal clinical outcome. J Matern Fetal Neonatal Med 23:1225-1229

5. Blaicher W, Hausler M, Gembruch U, Bollmann R, Terinde R, Rempen A, Deutinger J, Bernaschek G (2005) Feto-amniotic shunting - experience of six centres. Ultraschall Med 26:134-141

6. Deeks JJ, Altman DG, Bradburn MJ (2001) Statistical methods for examining heterogeneity and combining results from several studies in meta-analysis. BMJ Books, London

7. Derderian SC, Trivedi S, Farrell J, Keller RL, Rand L, Goldstein R, Feldstein VA, Hirose S, Mackenzie TC (2014) Outcomes of fetal intervention for primary hydrothorax. J Pediatr Surg 49:900-903 discussion 903-4

8. Deurloo KL, Devlieger R, Lopriore E, Klumper FJ, Oepkes D (2007) Isolated fetal hydrothorax with hydrops: a systematic review of prenatal treatment options. Prenat Diagn 27:893-899
9. Estoff JA, Parad RB, Frigoletto FD Jr, Benacerraf BR (1992) The natural history of isolated fetal hydrothorax. Ultrasound Obstet Gynecol 2:162-165

10. Henderson LK, Craig JC, Willis NS, Tovey D, Webster AC (2010) How to write a Cochrane systematic review. Nephrology (Carlton) 15:617-624

11. Jeong BD, Won HS, Lee MY, Shim JY, Lee PR, Kim A (2015) Perinatal outcomes of fetal pleural effusion following thoracoamniotic shunting. Prenat Diagn 35:1365-1370

12. Khan K, Riet GT, Glanville J, Sowden A, Kleijnen J (2000) Undertaking systematic reviews of research on effectiveness. CRD's guidance for carrying out or commissioning reviews, 2nd edn. NHS Centre for Reviews and Dissemination, University of York, York

13. Mallmann MR, Geipel A, Bludau M, Matil K, Gottschalk I, Hoopmann M, Muller A, Bachour H, Heydweiller A, Gembruch U, Berg C (2014) Bronchopulmonary sequestration with massive pleural effusion: pleuroamniotic shunting vs intrafetal vascular laser ablation. Ultrasound Obstet Gynecol 44:441-446

14. Moher D, Liberati A, Tetzlaff J, Altman DG (2009) Preferred reporting items for systematic reviews and meta-analyses: the PRISMA statement. J Clin Epidemiol 62:1006-1012

15. O'brien B, Kesby G, Ogle R, Rieger I, Hyett JA (2015) Treatment of primary fetal hydrothorax with OK-432 (Picibanil): outcome in 14 fetuses and a review of the literature. Fetal Diagn Ther 37:259 266

16. Pellegrinelli JM, Kohler A, Kohler M, Weingertner AS, Favre R (2012) Prenatal management and thoracoamniotic shunting in primary fetal pleural effusions: a single centre experience. Prenat Diagn 32:467-471

17. Petersen S, Kaur R, Thomas JT, Cincotta R, Gardener G (2013) The outcome of isolated primary fetal hydrothorax: a 10-year review from a tertiary center. Fetal Diagn Ther 34:69-76

18. Rennie D (2003) Improving reports of studies of diagnostic tests: the STARD initiative. JAMA 289:89-90

19. Rustico MA, Lanna M, Coviello D, Smoleniec J, Nicolini U (2007) Fetal pleural effusion. Prenat Diagn 27:793-799

20. Smith RP, Illanes S, Denbow ML, Soothill PW (2005) Outcome of fetal pleural effusions treated by thoracoamniotic shunting. Ultrasound Obstet Gynecol 26:63-66

21. Stroup DF, Berlin JA, Morton SC, Olkin I, Williamson GD, Rennie D, Moher D, Becker BJ, Sipe TA, Thacker SB (2000) Metaanalysis of observational studies in epidemiology: a proposal for reporting. Meta-analysis Of Observational Studies in Epidemiology (MOOSE) group. JAMA 283:2008-2012

22. Takahashi Y, Kawabata I, Sumie M, Nakata M, Ishii K, Murakoshi T, Katsuragi S, Ikeda T, Saito M, Kawamoto H, Hayashi S, Sago H (2012) Thoracoamniotic shunting for fetal pleural effusions using a double-basket shunt. Prenat Diagn 32:1282-1287

23. von Elm E, Altman DG, Egger M, Pocock SJ, Gotzsche PC, Vandenbroucke JP (2007) The Strengthening the Reporting of Observational Studies in Epidemiology (STROBE) statement: guidelines for reporting observational studies. PLoS Med 4:e296

24. Yinon Y, Kelly E, Ryan G (2008) Fetal pleural effusions. Best Pract Res Clin Obstet Gynaecol 22:77-96

\section{Summary}

In a pregnancy complicated by a fetus with primary hydrothorax and no other identifiable anomaly, we wished to determine whether pleuralamniotic shunt insertion was better than conservative management in terms of mortality. To do this, we conducted a systematic review between 1992 and 2017 and identified seven studies from which we could extract data. There was a paucity of comparative data with only two studies allowing for direct comparison. Within the limitations of the review, there was no difference between shunt insertion and conservative management. 


\section{Impact statement}

What is already known on this subject?

In a fetus with bilateral hydrothorax, which is hydropic, clinicians will often insert a thoracoamniotic shunt, as conservative management will often result in fetal demise. However, in the absence of hydrops, it is not clear whether shunt insertion or conservative management is preferable.

What do the results of this study add?

In fetuses with bilateral hydrothorax but no hydrops, our study indicates that there is insufficient evidence to determine if shunt insertion is better than conservative management.
What are the implications of these findings for clinical practice and/or further research?

The lack of evidence demonstrated by our systematic review highlights the need for fetal anomaly registries with standardized definitions, outcome measures, and follow-up.

Publisher's note Springer Nature remains neutral with regard to jurisdictional claims in published maps and institutional affiliations. 